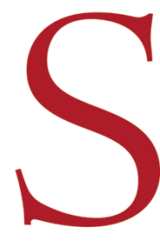

This is an enhanced PDF from The Journal of Bone and Joint Surgery

The PDF of the article you requested follows this cover page.

\title{
Fate of Untreated Asymptomatic Osteonecrosis of the Femoral Head
}

Kwang Woo Nam, Yong Lae Kim, Jeong Joon Yoo, Kyung-Hoi Koo, Kang Sup Yoon and Hee Joong Kim J Bone Joint Surg Am. 2008;90:477-484. doi:10.2106/JBJS.F.01582

This information is current as of December 23, 2009

Supplementary material

Reprints and Permissions

Publisher Information
Commentary and Perspective, data tables, additional images, video clips and/or translated abstracts are available for this article. This information can be accessed at http://www.ejbjs.org/cgi/content/full/90/3/477/DC1

Click here to order reprints or request permission to use material from this article, or locate the article citation on jbjs.org and click on the [Reprints and Permissions] link.

The Journal of Bone and Joint Surgery

20 Pickering Street, Needham, MA 02492-3157

www.jbjs.org 


\title{
Fate of Untreated Asymptomatic Osteonecrosis of the Femoral Head
}

\author{
By Kwang Woo Nam, MD, Yong Lae Kim, MD, Jeong Joon Yoo, MD, Kyung-Hoi Koo, MD, \\ Kang Sup Yoon, MD, and Hee Joong Kim, MD \\ Investigation performed at the Department of Orthopaedic Surgery, Seoul National University College of Medicine, Seoul, South Korea
}

\begin{abstract}
Background: Magnetic resonance imaging has made it possible to detect asymptomatic lesions of osteonecrosis of the femoral head before abnormalities appear on plain radiographs. The extent of a necrotic lesion is known to be an important prognostic factor. In this study, we evaluated the fate of untreated asymptomatic osteonecrosis of the femoral head with an emphasis on the size of the lesion. We hypothesized that a lesion smaller than a certain size would not progress to symptomatic disease.
\end{abstract}

Methods: One hundred and five initially asymptomatic hips of patients with bilateral nontraumatic osteonecrosis of the femoral head who had been followed without any treatment for at least five years or until pain developed were enrolled in this study. The extent of a lesion was estimated according to the area of the lesion based on a two-dimensional analysis on magnetic resonance images or on plain radiographs at the time of diagnosis.

Results: Sixty-two hips became symptomatic, and forty-three hips remained asymptomatic for more than five years (average, eight years and seven months). Of the twenty-one hips with a small necrotic lesion $(<30 \%$ of the area of the femoral head), one became painful; of the twenty-four hips with a medium-sized necrotic lesion ( $30 \%$ to $50 \%$ of the area of the femoral head), eleven became painful; and of the sixty hips with a large necrotic lesion ( $>50 \%$ of the area of the femoral head), fifty became painful. Forty-six of the sixty-two hips that became symptomatic required surgery. Pain developed within five years after the diagnosis in fifty-eight (94\%) of the sixty-two symptomatic hips.

Conclusions: No treatment appears to be necessary for asymptomatic necrotic lesions with an area smaller than $30 \%$ of the femoral head, as the vast majority of these lesions will remain asymptomatic for more than five years.

Level of Evidence: Prognostic Level II. See Instructions to Authors for a complete description of levels of evidence.

$\mathrm{M}$ ost of the literature regarding the natural history of nontraumatic osteonecrosis of the femoral head has concerned symptomatic osteonecrosis ${ }^{1-6}$. Symptomatic osteonecrosis of the femoral head that is not treated generally progresses to collapse, and eventually painful osteoarthritis develops ${ }^{7-11}$. However, the fate of untreated asymptomatic osteonecrosis of the femoral head remains unclear.

With the advent of magnetic resonance imaging, it is possible to make an early diagnosis of osteonecrosis before radiographic evidence appears. In particular, magnetic resonance imaging has made it easier to detect asymptomatic lesions in patients with osteonecrosis of the femoral head because most asymptomatic disease is not apparent radiographically ${ }^{11}$.

Many variables, such as disease stage, lesion size or location, the presence of pain, and radiographic evidence of collapse, have been evaluated as factors in the prognosis of osteonecrosis of the femoral head, and, of these, the extent of the necrotic lesion has been considered the most important ${ }^{11-18}$.

In the present study, we investigated the fate of untreated asymptomatic osteonecrosis of the femoral head on the basis of the hypothesis that asymptomatic lesions that were smaller than a certain size would not progress to symptomatic disease without treatment.

Disclosure: The authors did not receive any outside funding or grants in support of their research for or preparation of this work. Neither they nor a member of their immediate families received payments or other benefits or a commitment or agreement to provide such benefits from a commercial entity. No commercial entity paid or directed, or agreed to pay or direct, any benefits to any research fund, foundation, division, center, clinical practice, or other charitable or nonprofit organization with which the authors, or a member of their immediate families, are affiliated or associated. subscription department, at 781-449-9780, to order the CD-ROM). 
The Journal of Bone \& Joint Surgery - Jbjs.org Volume 90-A - Number $3 \cdot$ March 2008
Fate of Untreated Asymptomatic Osteonecrosis of the Femoral Head

\section{Materials and Methods}

E rom January 1982 to March 2005, 312 patients with biA lateral nontraumatic osteonecrosis of the femoral head presented to our department with pain in only one hip. The diagnosis of nontraumatic osteonecrosis of the femoral head was made on the basis of typical findings on plain radiographs and/or magnetic resonance images. Patients in whom osteonecrosis had developed after a femoral neck fracture or a hip dislocation were excluded. Of the 312 patients with an asymptomatic hip, 128 were treated with a joint-preserving procedure such as core decompression with or without bone-grafting, multiple drilling, or transtrochanteric rotational osteotomy. The remaining 184 were followed without any treatment for the asymptomatic hip. Included in this group were patients in whom no joint-preserving operation was recommended because they were older than fifty-five years of age as well as patients who were younger than fifty-five years of age and were advised to have a joint-preserving operation but refused it. Seventy-nine hips that remained asymptomatic but were followed for less than five years were excluded, leaving 105 hips to be included in the final analysis. All of those hips were followed for at least five years or until pain developed. Informed consent was obtained from all patients for participation in the study, which was approved by the institutional review board at our institute.

There were eighty-four men and twenty-one women with a mean age of fifty years (range, twenty-three to seventythree years) at the time of the diagnosis. According to the grading system described by Steinberg et al. ${ }^{15}$, sixty-two hips $(59 \%)$ were in stage I (normal findings on radiographs but abnormal findings on magnetic resonance images) and fortythree hips were in stage II (radiographs showing scleroses or cysts but no crescent sign) at the time of diagnosis. The mean duration of follow-up was seven years and eight months (range, ten months to twenty-two years and eight months). The risk factors associated with osteonecrosis were alcohol abuse (fiftyfour hips) and corticosteroid intake (twenty hips). Thirty-one hips were considered to have idiopathic osteonecrosis.

The extent of the necrotic lesions was measured on magnetic resonance images when available (seventy-eight hips) or on plain radiographs (twenty-seven hips) at the time of the diagnosis. Details of the method of measurement and its accuracy and repeatability have been previously described ${ }^{19}$. In brief, we measured the largest mediolateral diameter of the femoral head (R) and the longest mediolateral length of the necrotic lesion (A) on coronal magnetic resonance images or on anteroposterior plain radiographs, and the largest anteroposterior diameter of the femoral head $\left(\mathrm{R}^{\prime}\right)$ and the longest anteroposterior length of the necrotic lesion (B) on sagittal magnetic resonance images or on frog-leg lateral plain radiographs. The two-dimensional extent of a necrotic lesion was determined with the equation: $\%$ area $=\left(A \times B / R \times R^{\prime}\right) \times 100$ (Figs. 1-A and 1-B).

The location of a necrotic lesion was classified as Type A (less than the medial one-third of the weight-bearing area, medial location), B (between the medial one-third and two- thirds of the weight-bearing area, central location), and $\mathrm{C}$ (greater than the medial two-thirds of the weight-bearing area, lateral location) with use of the grading system described by Nishii et al. ${ }^{5}$ on the midcoronal T1-weighted magnetic resonance images (in seventy-eight hips) or on the anteroposterior radiographs (in twenty-seven hips). Twenty-two hips were classified as Type A; twenty-eight, as Type B; and fifty-five, as Type C.

Demographic and clinical differences between hips that remained painless and those that became painful were assessed.

\section{Statistical Analysis}

Nominal data were analyzed with use of the chi-square test and continuous data, with the Student t test.

Three subgroups were defined according to the size of the necrotic lesion: hips with necrosis of $<30 \%$ of the area of the femoral head, those with necrosis between $30 \%$ and $50 \%$ of the area, and hips with necrosis of $>50 \%$ of the area. Survival curves for these three groups were calculated with use of the Kaplan-Meier method, with the development of pain as the end point, and the time until pain developed was compared among the three groups with use of the log-rank test. The same analyses were done for the three types of lesion location.

We performed two different regression analyses. Linear regression analysis (a method used to analyze the relationship between two variables, $\mathrm{X}$ and $\mathrm{Y}$ ) was conducted to determine the relationship between the extent of the necrosis and the time until pain developed in the hips that became painful. Multivariate analyses were performed with use of the Cox proportional-hazards model (a method used to investigate the effects of the predictor variables on the time that an event takes to happen) to identify independent factors with regard to disease progression, defined as the development of pain. These analyses were adjusted for age, gender, body mass index, association with alcohol abuse and corticosteroid intake, and initial stage. The level of significance was set at $\mathrm{p}<0.05$.

\section{Results}

The mean extent of the 105 necrotic lesions was $52.9 \%$ (range, $2 \%$ to $100 \%$ ) of the area of the femoral head. Sixty-two hips (59\%) became painful and collapsed during the follow-up period, and forty-three hips (41\%) remained asymptomatic and without collapse for more than five years (mean, eight years and seven months; range, five to fifteen years).

Of the forty-three hips that remained asymptomatic, thirteen that had been in stage I progressed to stage II; however, eleven hips in stage I and nineteen hips in stage II remained in the same stage without evidence of femoral head collapse at the time of the latest follow-up. All of the sixty-two hips that became painful had progressed to femoral head collapse: eight hips progressed from stage I to III; twenty-six, from stage I to IV; three, from stage I to V; one, from stage I to VI; three, from stage II to III; seventeen, from stage II to IV; two from stage II to V; and two, from stage II to VI. The development of pain had a significant correlation with the occurrence of femoral head collapse $(\mathrm{p}<0.0001)$. 
The Journal of Bone \& Joint Surgery $\cdot$ JbJs.org Volume 90-A · Number $3 \cdot$ March 2008
Fate of Untreated Asymptomatic Osteonecrosis of the Femoral Head

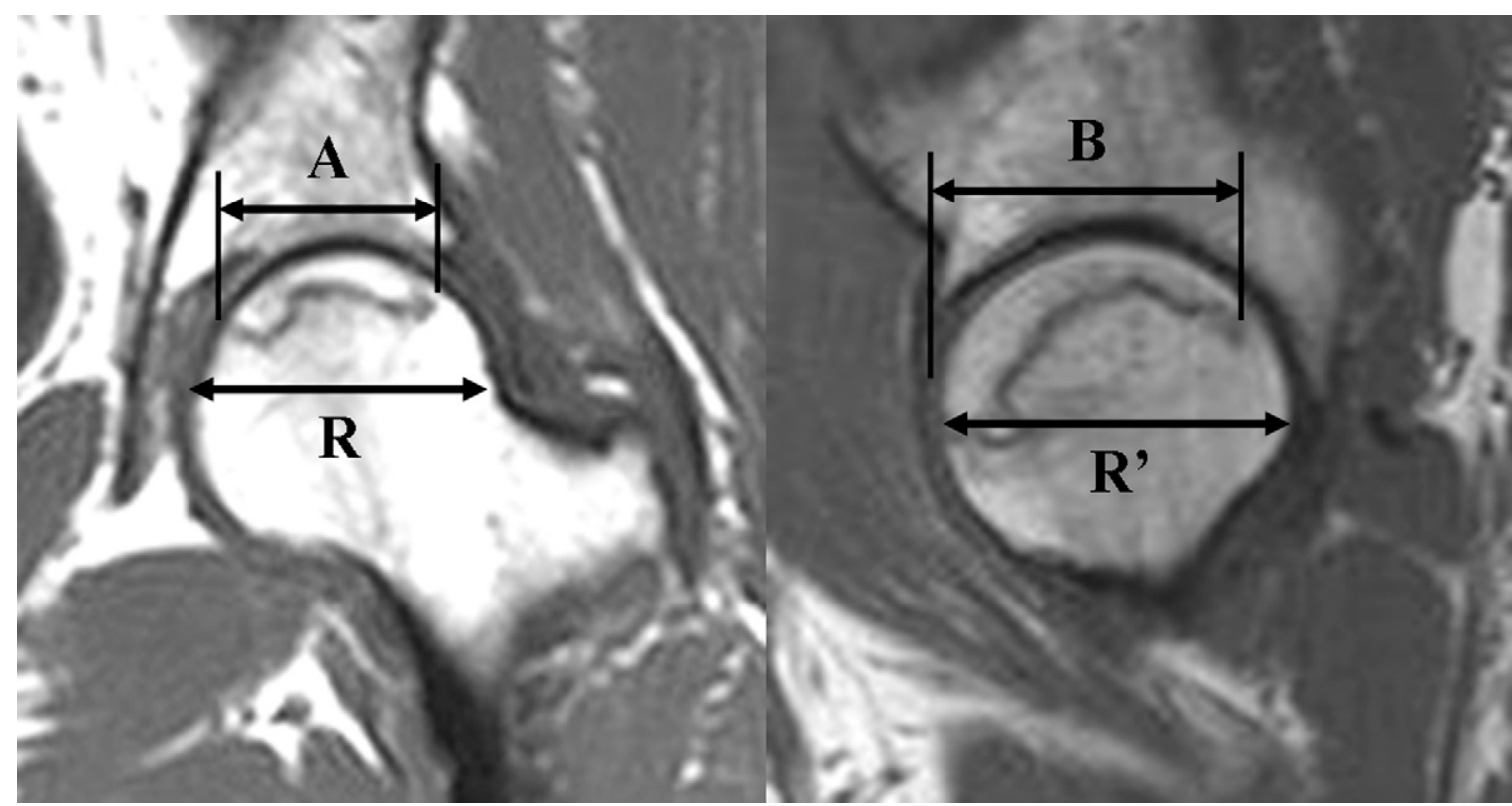

Fig. 1-A

Figs. 1-A and 1-B Details of the method for measuring the percent area (extent) of a necrotic lesion. The extent of a necrotic portion was determined with use of the equation: \% extent $=\left(A \times B / R \times R^{\prime}\right) \times 100$, where $R=$ the largest mediolateral diameter of the femoral head, $\mathrm{R}^{\prime}=$ the largest anteroposterior diameter of the femoral head, $A=$ the longest mediolateral length of the necrotic lesion, and $\mathrm{B}=$ the longest anteroposterior length of the necrotic lesion. Fig. 1-A Measurements on coronal and sagittal magnetic resonance images.

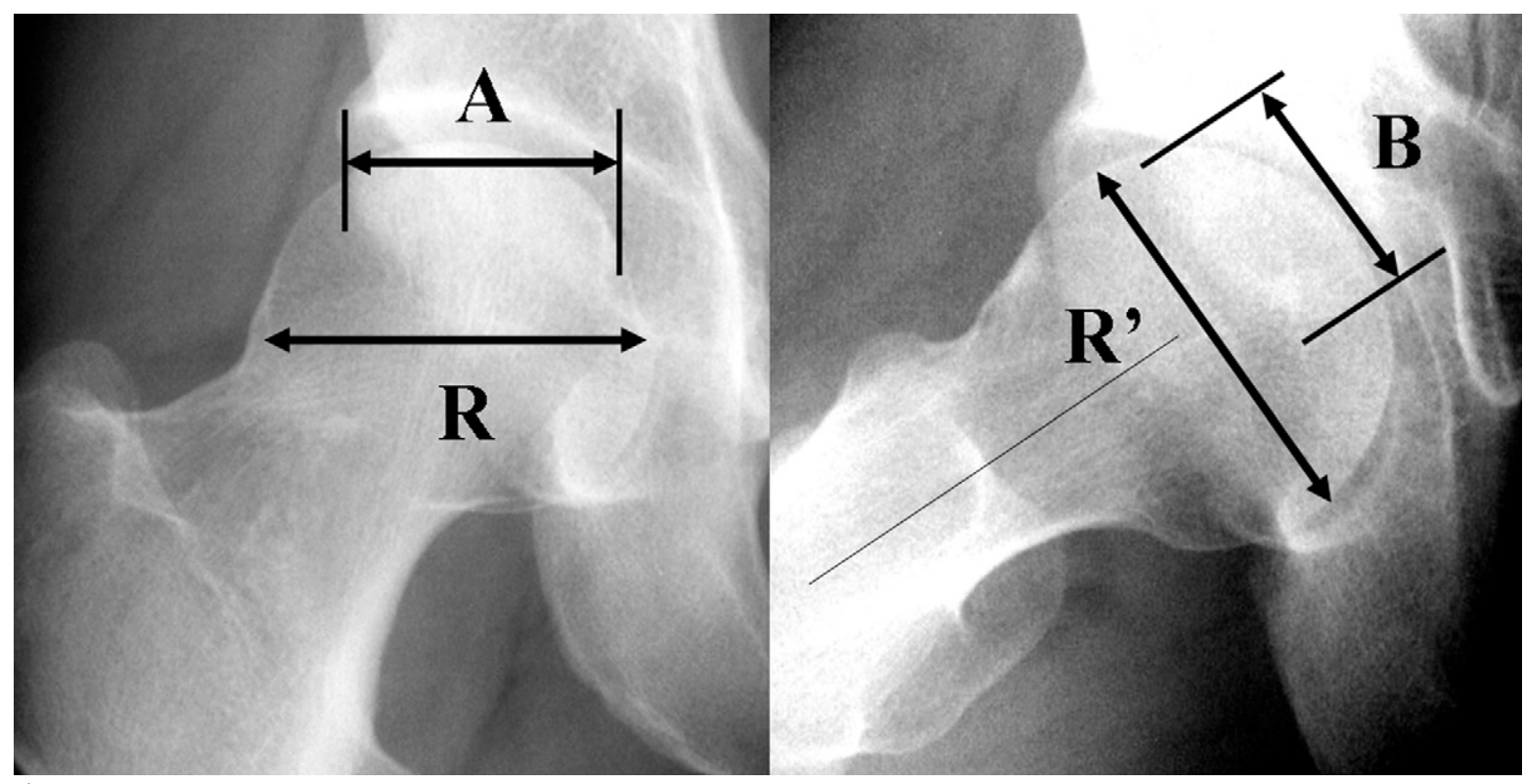

Fig. 1-B

Measurements on anteroposterior and frog-leg lateral radiographs.

The mean interval between the initial diagnosis and the development of pain was two years and one month (range, one month to eleven years). In the majority (fifty-eight) of sixty-two symptomatic hips, pain developed within five years. The pain developed within one year in twenty-five hips (40\%), within two years in forty-one (66\%), within three years in forty-seven $(76 \%)$, within four years in fifty-two $(84 \%)$, within five years in fifty-eight (94\%), and within ten years in sixty-one (98\%). (The numbers of hips are cumulative.) A smaller extent of necrosis was found to be significantly associated with a longer time between the diagnosis and the development of pain $(\mathrm{p}=0.008$, time to pain [in months] $=58.3-0.499 \times \%$ area of necrosis).

With the numbers studied, age, gender, and body mass index were not found to be significantly associated with the 


\section{TABLE I Comparison of Data Between Hips That Remained Painless for More Than Five Years and Hips That Became Symptomatic}

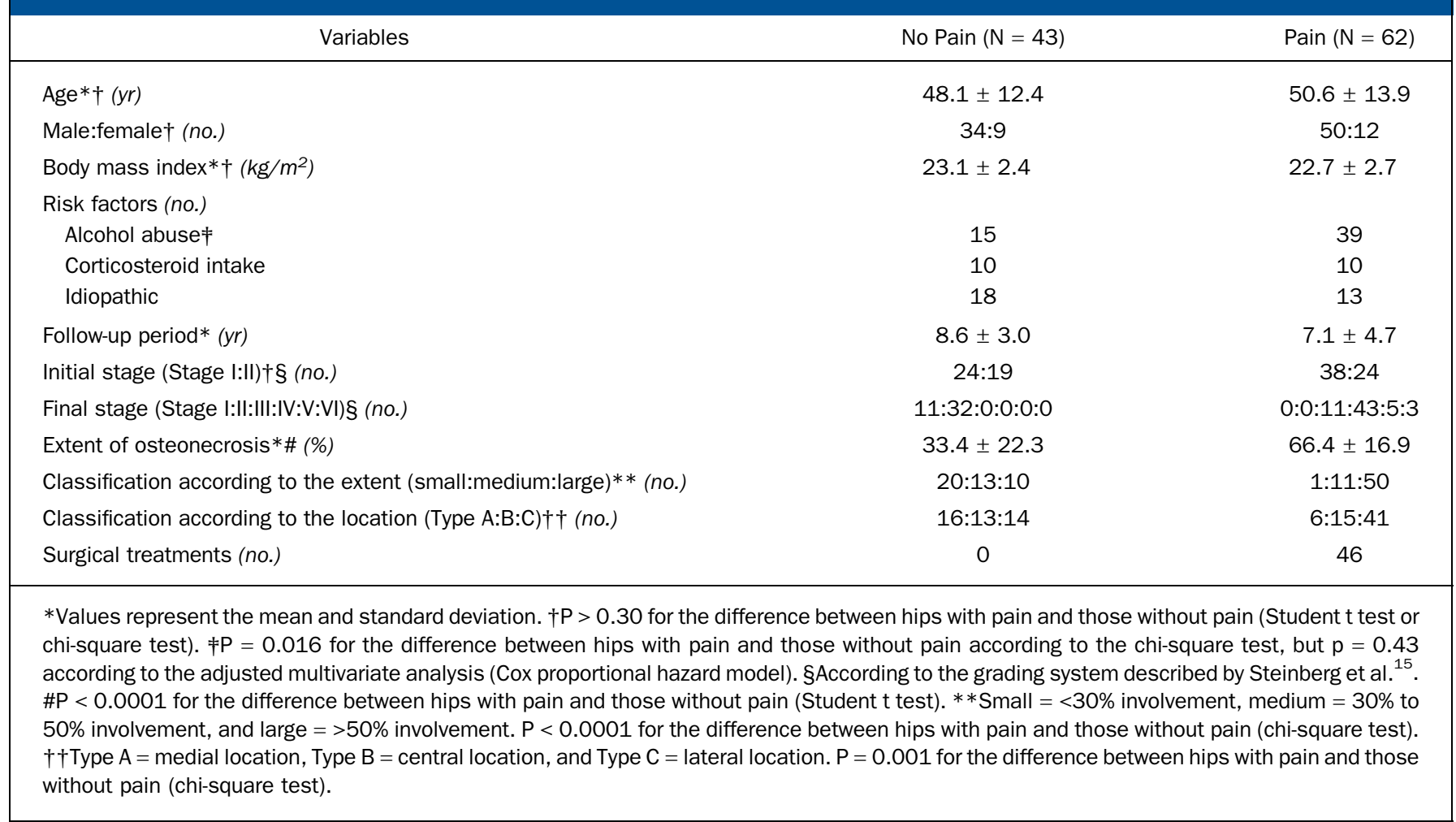

development of pain ( $p>0.30$ for all, Table I). Cases related to alcohol abuse became symptomatic more often than did those related to corticosteroid intake or idiopathic causes. However, multivariate analysis showed no significant relationship, with the numbers available, between these risk factors and the development of pain after adjustment for other variables, including age, gender, body mass index, initial stage, lesion extent, and lesion location ( $p=0.43$ ). No significant difference was found between stage-I hips and stage-II hips with regard to the development of pain $(\mathrm{p}=0.58)$.

The extent of the necrotic lesion was found to be significantly greater in the hips that became symptomatic ( $\mathrm{p}<$ 0.0001 ), and adjusted multivariate analyses showed it to be a significant independent predictor of disease progression (defined as the development of pain) ( $p<0.0001$, Table II). An increase in the extent of osteonecrosis by $1 \%$ was found to be associated with a 1.029-fold increase in the risk of pain developing (95\% confidence interval, 1.014 to 1.045$)$.

The lesion location was found to be significantly associated with the development of pain $(p=0.001)$, but it was not found to be a significant independent predictor of disease progression in the adjusted multivariate analysis $(\mathrm{p}=0.3)$. Pain developed in six of the twenty-two Type-A hips, fifteen of the twenty-eight Type-B hips, and forty-one of the fifty-five Type-C hips. With the development of pain as the end point, a comparison of survival curves showed no significant differences among the three types $(\mathrm{p}=0.23)$.
Of the sixty-two hips in which pain developed, forty-six (74\%) deteriorated sufficiently to require surgery and fortyfour of these were treated operatively; bipolar arthroplasty was performed in three hips and total hip arthroplasty, in forty-one hips. The remaining two patients were awaiting surgery at the time of their latest follow-up. The average time between the onset of pain and surgery was one year and seven months (range, one month to ten years and ten months). Sixteen of the sixty-two hips in which pain developed remained untreated at

\begin{tabular}{|c|c|c|}
\hline Variable & $\begin{array}{l}\text { Hazards Ratio } \\
\text { (95\% Confidence } \\
\text { Interval) }\end{array}$ & P Value \\
\hline $\begin{array}{l}\text { Size (1\% increment in } \\
\text { lesion size } \dagger)\end{array}$ & $1.029(1.014-1.045)$ & $<0.0001$ \\
\hline Large (>50\% involvement) & $13.540(1.849-99.164)$ & 0.010 \\
\hline Type C (lateral location) & $1.604(0.657-3.915)$ & 0.300 \\
\hline \multicolumn{3}{|c|}{$\begin{array}{l}\text { *Analysis adjusted for age, gender, body mass index, association } \\
\text { with alcohol abuse and corticosteroid intake, and initial stage. } \\
\dagger \text { The hazard to pain development increases } 2.9 \% \text { for each } 1 \% \\
\text { increment in size. }\end{array}$} \\
\hline
\end{tabular}


The Journal of Bone \& Joint Surgery $\cdot$ Jbjs.org Volume 90-A · Number $3 \cdot$ March 2008
Fate of Untreated Asymptomatic Osteonecrosis of the Femoral Head

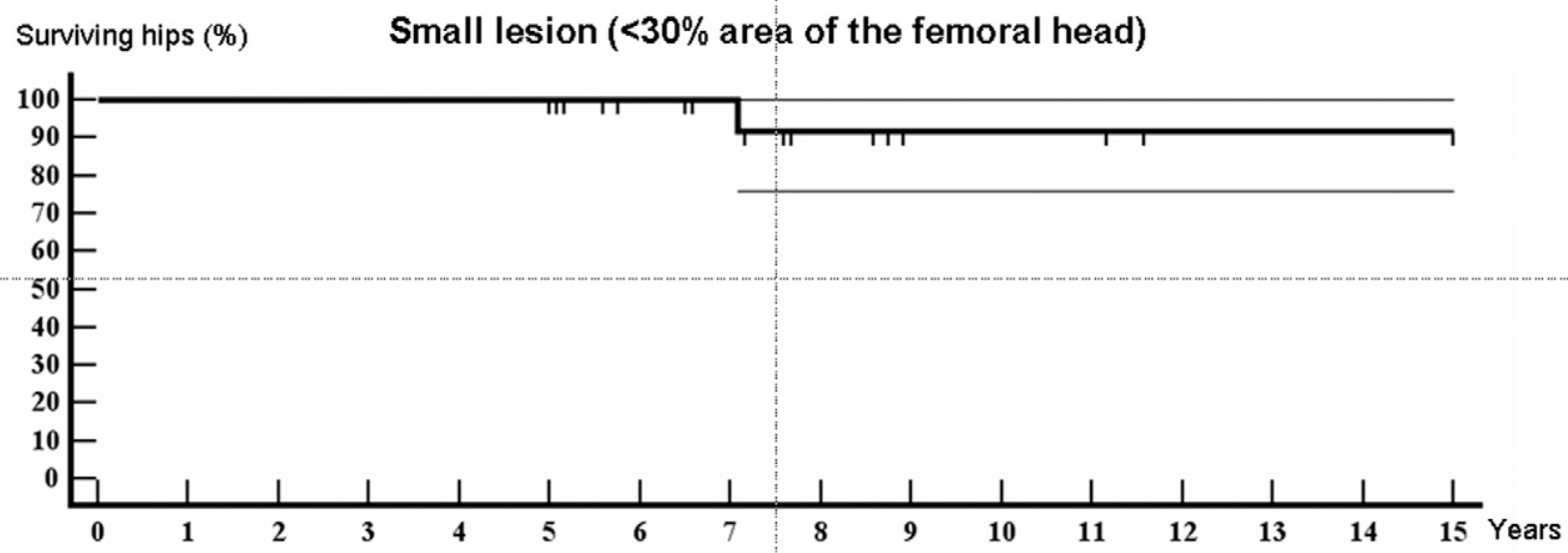

Fig. 2-A

Figs. 2-A, 2-B, and 2-C Kaplan-Meier survivorship curves, with 95\% confidence intervals, for the hips with different sizes of necrotic lesion, with the development of pain as the end point. Asymptomatic hips were classified into three groups according to the extent of the necrotic lesion. Differences between all groups were significant (log-rank test, $p=0.0006$ ). Fig. 2-A Hips with a small lesion (involvement of $<30 \%$ of the area of the femoral head).

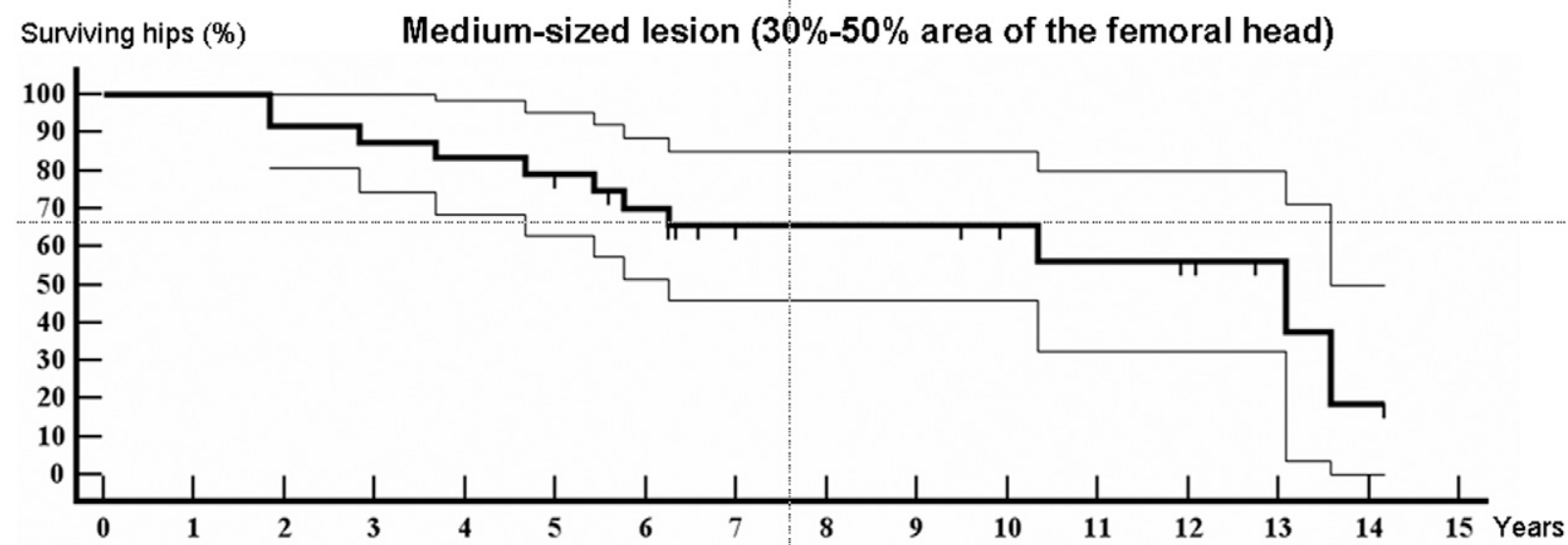

Fig. 2-B

Hips with a medium-sized lesion (involvement of $30 \%$ to $50 \%$ of the area of the femoral head).

\section{Surviving hips (\%) Large lesion ( $>50 \%$ area of the femoral head)}

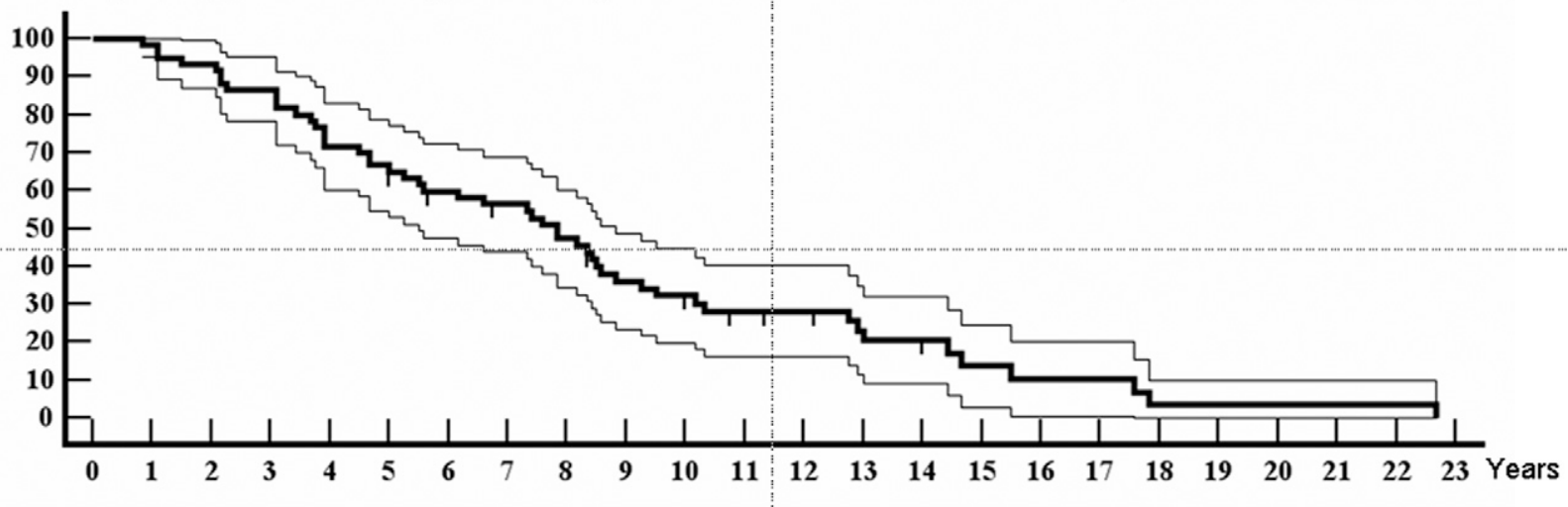

Fig. 2-C

Hips with a large lesion (involvement of $>50 \%$ of the area of the femoral head). 
The Journal of Bone \& Joint Surgery $\cdot$ JBJS.org VOLUMe 90-A • Number $3 \cdot$ MarCh 2008
Fate of Untreated Asymptomatic Osteonecrosis

of the Femoral Head

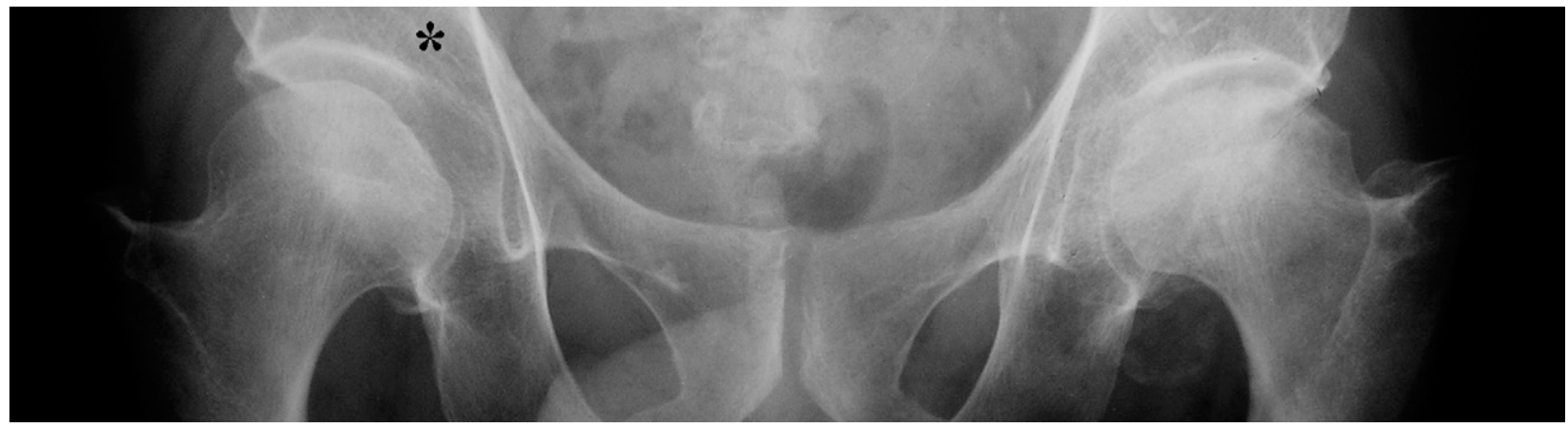

Fig. 3-A

Figs. 3-A, 3-B, and 3-C A patient with osteonecrosis that remained painless despite substantial femoral head involvement. Fig. 3-A Anteroposterior radiograph showing a right asymptomatic hip in stage I (asterisk) and a left symptomatic hip in stage IV at the time of diagnosis.

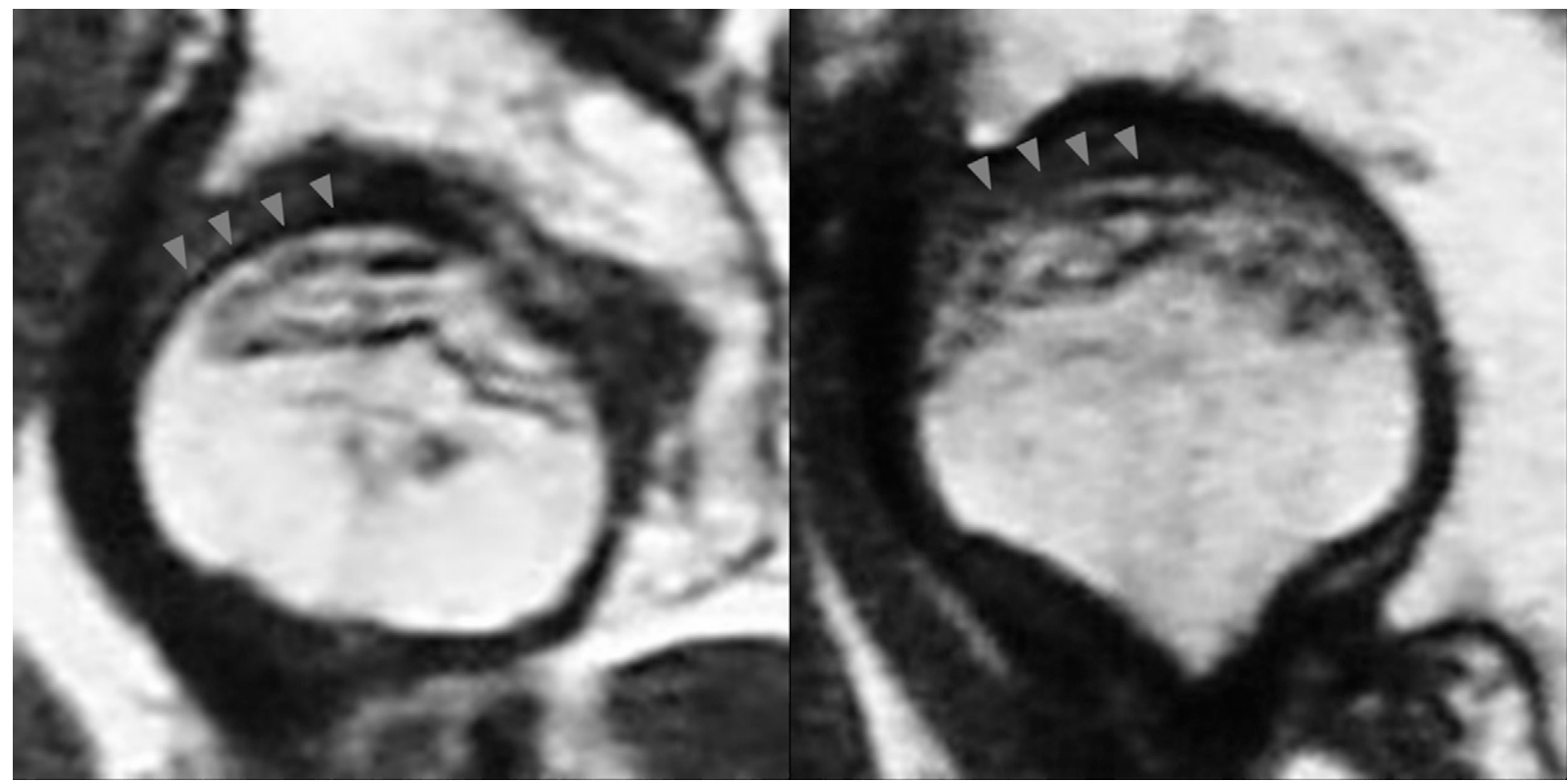

Fig. 3-B

A coronal T1-weighted magnetic resonance image of the right hip (left image) shows a central necrotic lesion with normal bone between the lesion and the articular cartilage of the weight-bearing portion (arrowheads), and a sagittal T1-weighted magnetic resonance image (right image) also shows the lesion, with sparing of subchondral bone (arrowheads). This lesion was estimated to involve up to $76 \%$ of the femoral head.

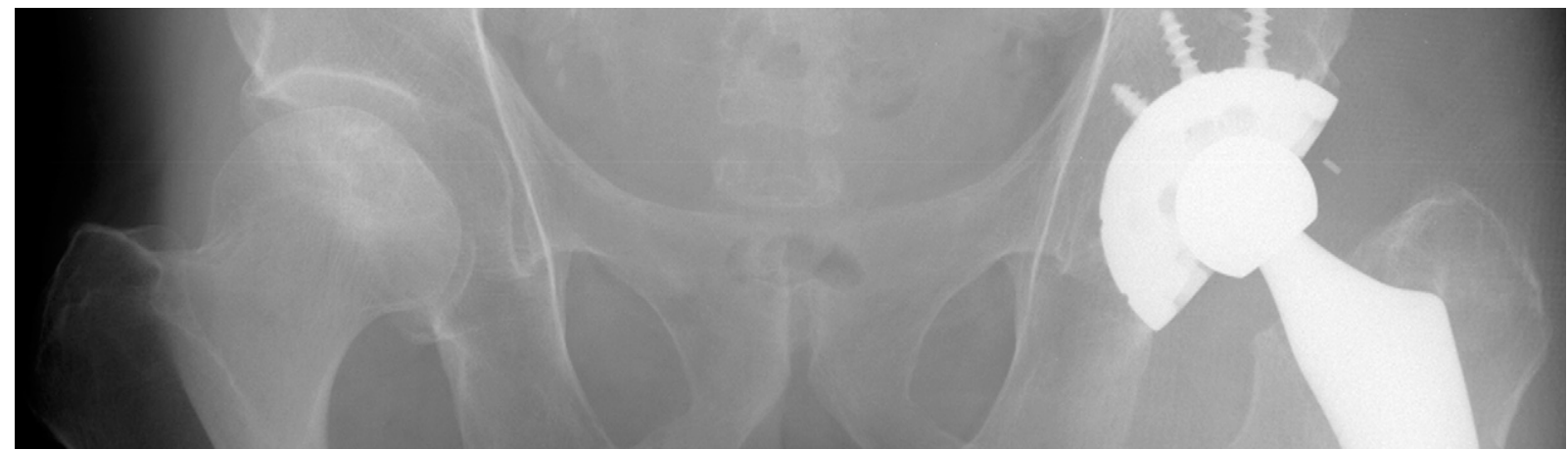

Fig. 3-C

The right hip was still asymptomatic without collapse at the time of final follow-up, at eleven years and four months. The left hip was replaced four weeks after the diagnosis. 
The Journal of Bone \& Joint Surgery · Jbjs.org Volume 90-A - Number $3 \cdot$ March 2008
Fate of Untreated Asymptomatic Osteonecrosis of the Femoral Head the time of final follow-up, as the pain was not severe enough to warrant surgery. A significant difference in the mean lesion size was noted between the sixteen untreated hips $(53.3 \%$ of the area of the femoral head) and the forty-six hips that required surgery $(70.9 \%$ of the area) $(p<0.0001)$.

Of the twenty-one hips with a small lesion $(<30 \%$ of the area of the femoral head), one became symptomatic; of the twenty-four hips with a medium-sized lesion (30\% to $50 \%$ of the area), eleven became symptomatic; and of the sixty hips with a large lesion ( $>50 \%$ of the area), fifty became symptomatic. With the development of pain as the end point, a comparison of survival curves showed that hips with a small lesion had a significantly longer survival duration than those with a medium-sized or large lesion $(\mathrm{p}=0.0096$ and 0.0002 , respectively) (Figs. 2-A, 2-B, and 2-C). The one hip with a small lesion that became painful had a far-lateral lesion, and the ten large lesion hips that remained painless had a central lesion with normal bone between the necrotic lesion and the articular cartilage (that is, the subchondral bone was spared) (Figs. 3-A, 3-B, and 3-C).

\section{Discussion}

D revious studies of asymptomatic osteonecrosis of the femoral head have demonstrated various rates of disease progression $^{5,20-28}$. Differing opinions regarding the fate of asymptomatic disease have been attributed to several reasons, including differences in study populations, diagnostic modalities, follow-up periods, and the definition of disease progression ${ }^{5,27}$. In the present study, 105 asymptomatic hips with early stages of disease were not treated. Sixty-two hips were followed until pain developed, and the other forty-three remained painless without collapse for five years or more. Therefore, the overall rate of progression of asymptomatic osteonecrosis in this study was $59 \%$. These results are comparable with the overall rate of $66 \%$ (317 of 480) in the previous reports ${ }^{5,20-28}$ describing progression of asymptomatic disease. In our study, pain developed in most hips (83\%; fifty of sixty) in which the lesion involved $>50 \%$ of the femoral head, usually within three years $(76 \%$; forty-seven of sixty-two hips).

The cohort of this study did not comprise all patients with asymptomatic osteonecrosis of the femoral head. Patients younger than fifty-five years of age were included only when they had refused joint-preserving treatment. To minimize the effect of this selection, we recommended joint-preserving treatment to all patients younger than fifty-five years of age, regardless of the size of the necrotic lesion.

The extent of a necrotic lesion is an important determinant of prognosis ${ }^{11-18}$. The present study showed that, among the various factors evaluated, the extent of the necrotic lesion was the most important for predicting the prognosis of asymptomatic osteonecrosis of the femoral head. In this study, the rate of disease progression, defined as the development of pain, was $5 \%$ for small necrotic lesions ( $<30 \%$ of the area of the femoral head), $46 \%$ for medium-sized necrotic lesions ( $30 \%$ to $50 \%$ of the area), and $83 \%$ for large necrotic lesions ( $>50 \%$ of the area). While Hungerford and Jones ${ }^{11}$ and Steinberg et al. ${ }^{15}$ defined small lesions as $<15 \%$ of volume and large lesions as $>30 \%$ of volume, we defined small lesions as $<30 \%$ of area and large lesions as $>50 \%$ of area. We used percent of area because the measuring method was simple.

The results of this study suggest that the development of pain is related to the occurrence of femoral head collapse, a finding consistent with those reported by Nishii et al. ${ }^{5}$. In addition, we found that the extent of the lesion was related to the time that it took for pain to develop and the need for surgery. Pain developed more slowly and rarely progressed enough to require surgery in hips with smaller lesions.

We found that age, gender, body mass index, selected risk factors associated with osteonecrosis, and initial radiographic stage were not associated with the development of pain. These results are similar to those of earlier studies regarding the natural course of early-stage disease, whether asymptomatic or not ${ }^{5,12,18,24,25}$. In the present study, the extent of the lesion appeared to be more important than the initial radiographic stage as a factor in the fate of osteonecrosis of the femoral head, particularly in its earlier stages, an observation that is supported by the literature on the topic ${ }^{11,13,16,17,25}$.

Exceptional cases, in which a small lesion became painful or a large lesion remained painless, suggest that the location of the lesion is another important prognostic factor. In this study, lesion location was closely related to the development of pain, but it was not a significant prognostic factor for disease progression. This may be due to the fact that larger lesions usually extended more laterally in the femoral head.

In the current study, one small necrotic lesion that became painful was located far laterally in the femoral head. Nishii et al. ${ }^{5,18}$ reported a poor prognosis for lesions in this location despite a small size. Moreover, the ten large necrotic lesions that remained painless in our study were located in the central portion of the femoral head, and a substantial amount of subchondral bone above these lesions had been spared. This finding is consistent with reports by Ohzono et al. ${ }^{2}$ and Ito et al. $^{25}$, who also noted that centrally located lesions rarely progressed to collapse despite a large size.

Many authors have reported that small necrotic lesions remained asymptomatic for several years ${ }^{5,23-25,27}$. The results of the present study strongly suggest that asymptomatic necrotic lesions involving $<30 \%$ of the femoral head typically have a benign course for more than five years and do not need any treatment unless they are located far laterally. When pain developed in our series, it almost always did so within five years after the diagnosis. We are of the opinion that our duration of follow-up of small lesions that remained painless was adequate as it ranged from five to fifteen years and averaged seven years and ten months. Hernigou et al., in two separate studies ${ }^{26,28}$, reported that the majority of small asymptomatic osteonecrotic lesions became symptomatic; $88 \%$ of forty hips became symptomatic within a mean of six years and eight months after the diagnosis and $91 \%$ of 121 hips did so within three years after the diagnosis. The reason for this difference between their results and ours is uncertain but may be related to different study populations and different durations of follow-up. A 
The Journal of Bone \& JoInt Surgery $\cdot$ JBjS. org Volume 90-A · Number $3 \cdot$ MarCh 2008
Fate of Untreated Asymptomatic Osteonecrosis of the Femoral Head larger proportion of the patients in one of their studies ${ }^{26}$ (eleven of forty compared with twenty of 105 in our study) had steroid-related disease and were followed for a mean of eleven years, and, in their other study ${ }^{28}$, all patients had sickle cell disease and were followed for a mean of fourteen years.

We intend to continue observing the patients who were enrolled in the present study closely. Nevertheless, we believe that no treatment is necessary for asymptomatic necrotic lesions when they involve $<30 \%$ of the area of the femoral head, as calculated with our method.

Kwang Woo Nam, MD

Department of Orthopaedic Surgery, Cheju National University Hospital, 154 Samdo2dong, Jeju, 690-716, South Korea
Yong Lae Kim, MD

Department of Orthopaedic Surgery, Inchon Medical Center Hospital, 318-1 SongnimDong, DongGu, Inchon, 401-711, South Korea

Jeong Joon Yoo, MD

Hee Joong Kim, MD

Department of Orthopaedic Surgery (J.J.Y. and H.J.K.) and Medical Research Center (H.J.K.), Seoul National University Hospital, 28 Yongondong Chongnogu, Seoul, 110-744, South Korea.

E-mail address for H.J. Kim: oskim@snu.ac.kr

Kyung-Hoi Koo, MD

Department of Orthopaedic Surgery, Seoul National University Bundang Hospital, 300 Gumidong Bundanggu, Seongnam, 463-707, South Korea

Kang Sup Yoon, MD

Department of Orthopaedic Surgery, Seoul Municipal Boramae Hospital, 395 Shindaebangdong Dongjackgu, Seoul, 156-707, South Korea

\section{References}

1. Patterson RJ, Bickel WH, Dahlin DC. Idiopathic avascular necrosis of the head of the femur. A study of fifty-two cases. J Bone Joint Surg Am. 1964;46:267-82.

2. Ohzono K, Saito M, Takaoka K, Ono K, Saito S, Nishina T, Kadowaki T. Natural history of nontraumatic avascular necrosis of the femoral head. J Bone Joint Surg Br. 1991;73:68-72.

3. Fairbank AC, Bhatia D, Jinnah RH, Hungerford DS. Long-term results of core decompression for ischaemic necrosis of the femoral head. J Bone Joint Surg Br. 1995;77:42-9.

4. Mont MA, Carbone JJ, Fairbank AC. Core decompression versus nonoperative management for osteonecrosis of the hip. Clin Orthop Relat Res. 1996;324: 169-78.

5. Nishii T, Sugano N, Ohzono K, Sakai T, Haraguchi K, Yoshikawa H. Progression and cessation of collapse in osteonecrosis of the femoral head. Clin Orthop Relat Res. 2002;400:149-57.

6. Hernigou P, Bachir D, Galacteros F. The natural history of symptomatic osteonecrosis in adults with sickle-cell disease. J Bone Joint Surg Am. 2003;85:500-4.

7. Meyers MH. Osteonecrosis of the femoral head. Pathogenesis and long-term results of treatment. Clin Orthop Relat Res. 1988;231:51-61.

8. Mont MA, Hungerford DS. Non-traumatic avascular necrosis of the femoral head. J Bone Joint Surg Am. 1995;77:459-74.

9. Hungerford DS. Osteonecrosis: avoiding total hip arthroplasty. J Arthroplasty. 2002;17(4 Suppl 1):121-4.

10. Belmar CJ, Steinberg ME, Hartman-Sloan KM. Does pain predict outcome in hips with osteonecrosis? Clin Orthop Relat Res. 2004;425:158-62.

11. Hungerford DS, Jones LC. Asymptomatic osteonecrosis: should it be treated? Clin Orthop Relat Res. 2004;429:124-30.

12. Stulberg BN, Davis AW, Bauer TW, Levine M, Easley K. Osteonecrosis of the femoral head. A prospective randomized treatment protocol. Clin Orthop Relat Res. 1991;268:140-51.

13. Lafforgue $P$, Dahan $E$, Chagnaud $C$, Schiano A, Kasbarian M, Acquaviva PC. Early-stage avascular necrosis of the femoral head: MR imaging for prognosis in 31 cases with at least 2 years of follow-up. Radiology. 1993;187:199-204.

14. Takatori $Y$, Kokubo T, Ninomiya S, Nakamura S, Morimoto S, Kusaba I. Avascular necrosis of the femoral head. Natural history and magnetic resonance imaging. J Bone Joint Surg Br. 1993;75:217-21.
15. Steinberg ME, Hayken GD, Steinberg DR. A quantitative system for staging avascular necrosis. J Bone Joint Surg Br. 1995;77:34-41.

16. Koo KH, Kim R. Quantifying the extent of osteonecrosis of the femoral head. A new method using MRI. J Bone Joint Surg Br. 1995;77:875-80.

17. Steinberg ME, Bands RE, Parry S, Hoffman E, Chan T, Hartman KM. Does lesion size affect the outcome in avascular necrosis? Clin Orthop Relat Res. 1999;367:262-71.

18. Nishii T, Sugano N, Ohzono K, Sakai T, Sato Y, Yoshikawa H. Significance of lesion size and location in the prediction of collapse of osteonecrosis of the femoral head: a new three-dimensional quantification using magnetic resonance imaging. J Orthop Res. 2002;20:130-6.

19. Kim YM, Ahn JH, Kang HS, Kim HJ. Estimation of the extent of osteonecrosis of the femoral head using MRI. J Bone Joint Surg Br. 1998;80:954-8.

20. Lee CK, Hansen HT, Weiss AB. The "silent hip" of idiopathic ischemic necrosis of the femoral head in adults. J Bone Joint Surg Am. 1980;62:795-800.

21. Kopecky KK, Braunstein EM, Brandt KD, Filo RS, Leapman SB, Capello WN, Klatte EC. Apparent avascular necrosis of the hip: appearance and spontaneous resolution of MR findings in renal allograft recipients. Radiology. 1991;179:523-7.

22. Bradway JK, Morrey BF. The natural history of the silent hip in bilateral atraumatic osteonecrosis. J Arthroplasty. 1993;8:383-7.

23. Jergesen $\mathrm{HE}$, Khan AS. The natural history of untreated asymptomatic hips in patients who have non-traumatic osteonecrosis. J Bone Joint Surg Am. 1997;79:359-63.

24. Ito $H$, Matsuno $T$, Kaneda K. Prognosis of early stage avascular necrosis of the femoral head. Clin Orthop Relat Res. 1999;358:149-57.

25. Ito $\mathrm{H}$, Matsuno $\mathrm{T}$, Omizu $\mathrm{N}$, Aoki $\mathrm{Y}$, Minami A. Mid-term prognosis of nontraumatic osteonecrosis of the femoral head. J Bone Joint Surg Br. 2003;85: 796-801.

26. Hernigou $P$, Poignard $A$, Nogier $A$, Manicom $O$. Fate of very small asymptomatic stage-I osteonecrotic lesions of the hip. J Bone Joint Surg Am. 2004;86:2589-93.

27. Cheng EY, Thongtrangan I, Laorr A, Saleh KJ. Spontaneous resolution of osteonecrosis of the femoral head. J Bone Joint Surg Am. 2004;86:2594-9.

28. Hernigou $P$, Habibi $A$, Bachir D, Galacteros F. The natural history of asymptomatic osteonecrosis of the femoral head in adults with sickle cell disease. J Bone Joint Surg Am. 2006;88:2565-72. 